\title{
Flow Injection Determination of Thymol in Pharmaceutical Samples Via Oxidative Coupling Reaction with 2,4- Dinitrophenylhydrazine
}

\author{
Mouayed Q.Al-Abachi, Hind Hadi ${ }^{1}$ and Ghadah Fadhil \\ Department of Chemistry, College of Science, University of Baghdad, Baghdad-Iraq. \\ ${ }^{1}$ E-mail: hindhadi13@yahoo.com.
}

\begin{abstract}
A fast and sensitive flow injection analysis (FIA) method for the quantitative determination of thymol (THY) in raw and pharmaceutical formulations have been proposed. The method is based on coupling reaction between THY and 2,4-dinitrophenylhydrazine in alkaline medium with presence of potassium periodate to form an intense violet water-soluble dye that is stable and has a maximum absorption at $570 \mathrm{~nm}$. A graph of absorbance versus concentration indicates that Beer's law is obeyed over the concentration range of $10-150 \mu \mathrm{g} \cdot \mathrm{mL}^{-1}$ of THY, with detection limit of $5 \mu \mathrm{g} \cdot \mathrm{mL}^{-1}$ and sample throughputs of $60 \mathrm{~h}^{-1}$. The proposed method was successfully applied to the determination of THY in mouth wash preparations.
\end{abstract}

Keywords: Thymol, 2,4-dinitrophenylhydrazine, Flow injection spectrophotometry.

\section{Introduction:}

Thymol Fig.(1) is a natural monoterpene phenol derivative of cymene .The chemical name of thymol is a 2-isopropyl-5methylphenol, with a molecular weight of $150.2 \mathrm{~g} / \mathrm{mole}$ [1]. Thymol is only slightly soluble in water at neutral $\mathrm{pH}$, but it is extremely soluble in alcohols and other organic solvents. It is also soluble in strongly alkaline aqueous solutions due to deprotonation of the phenol.<smiles>Cc1ccc(C(C)C)c(O)c1</smiles>

Fig.(1) Structure of thymol.

Thymol absorbs maximum UV radiation at $274 \mathrm{~nm}$ [2]. THY is part of a naturally occurring class of compounds known as biocides, with strong antimicrobial attributes when used alone or with other biocides such as carvacrol. In addition, naturally occurring biocides agents such as THY can reduce bacterial resistance to common drugs such as penicillin. Research demonstrates that naturally occurring biocides such as THY and carvacrol reduce bacterial resistance to antibiotics through a synergistic effect, and THY has been shown to be an effective fungicide, particularly against fluconazole- resistant strains. THY has been shown to act as a positive allosteric modulator in vitro. THY is chemically related to the anesthetic propofol [3].

The literatures reported different methods for the estimation of THY, including chromatography [4-8], GC-MS [9,10], colorimetry [11], electrochemical sensor [12], spectrophotometry [13-15], solid-phase micro extraction-gas chromate-graphy [16-18] and Flow injection spectrophotometry [19]. On the other hand, some of these methods are suffering from some draw back such as time consuming and/or require expensive equipment or $\mathrm{pH}$ control.

In this paper, FI method using spectrophotometric detection at $570 \mathrm{~nm}$ is described for the determination of THY. The batch method [20] was adopted as a basis to develop a FIA-spectrophotometric method based on reaction between THY with 2,4dintrophenyhydrazin in alkaline medium with presence of potassium periodate. The analytical procedure is safe, simple, fast and accurate. It has been satisfactorily applied to the determination of THY in pure and mouth wash preparations.

\section{Experimental \\ Apparatus}

All spectral and absorbance measurements were carried out on a Shimadzu UV-Visble260 digital double-beam recording spectrophotometer (Tokyo-Japan), using 1-cm 
quartz cells. A quartz flow cell with $50 \mu \mathrm{L}$ internal volume and $1 \mathrm{~cm}$ bath length was used for the absorbance measurements. A two channel manifold Fig.(2) was employed for the FIA spectrophotometer determination of THY. A peristaltic pump (Ismatec, LabortechnikAnalytic, CH-8152, Glatbrugg-Zurich, Switzerland, six channels) was used to transport the reagents solutions, Injection valve (Rheodyne, Altex 210, Supelco-USA) which was employed to provide appropriate injection volumes of standard solutions and samples. Flexible vinyl tubing of $0.5 \mathrm{~mm}$ internal diameter was used for the peristaltic pump. Reaction coil (RC) was of Teflon with internal diameter of $0.5 \mathrm{~mm}$. In Fig.(2) 2,4dinitrophenylhydrazine (A) stream have been combined with injected sample and they merged with the mixture of potassium periodate with $\mathrm{NaOH}$ (B) stream at T-link then mixed in reaction coil (RC) with length of 100 $\mathrm{cm}$, injection loop of $(150 \mu \mathrm{L})$, total flow rate of $2.4 \mathrm{ml} / \mathrm{min}$, the absorbance has been measured at $570 \mathrm{~nm}$.

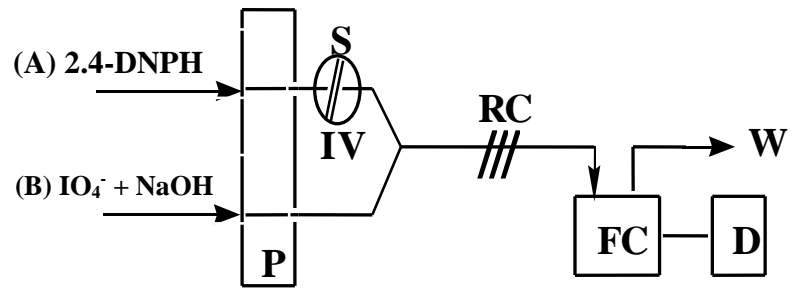

Fig.(2) A schematic diagram of FIA manifold Where: $(A)$ and $(B)$, solutions of 2,4dinitrophenylhydrazine and a mixture of potassium periodate with $\mathrm{NaOH}$ respectively; $P=$ peristaltic pump; $S=$ injection sample Thymol; $I V=$ injection valve; $R C=$ reaction coil; $F C=$ flow cell; $D=$ detector; $W=$ waste.

\section{Reagents and Materials}

- Thymol stock solution (1000 $\mu g . m L^{-1}$ $=0.06658 M, B D H)$ : The stock solution of THY was prepared by dissolving $0.1000 \mathrm{~g}$ in $5 \mathrm{~mL}$ of ethanol and completed to $100 \mathrm{~mL}$ with the same solvent. Serial dilutions with distilled water were made to cover the working range.

- 2,4-dinitrophenylhydrazine (2,4-DNPH) $\left(1 \times \mathbf{1 0}^{-3} \boldsymbol{M}\right)$ : These were freshly prepared by dissolving $0.0198 \mathrm{~g}$ of 2,4-DNPH $(\mathrm{BDH})$ in $2 \mathrm{~mL}$ of concentrated sulfuric acid and diluting to $100 \mathrm{~mL}$ with distilled water in volumetric flask.

- Sodium hydroxide (0.5M): This solution was prepared by dissolving $5 \mathrm{~g}$ of reagent $(\mathrm{BDH})$ in distilled water and made up to $250 \mathrm{~mL}$ with distilled water.

- A mixture of $0.5 \mathrm{M} \mathrm{NaOH}$ with $5 \times 10^{-3} \mathrm{M}$ of potassium periodate was prepared by dissolving $2 \mathrm{~g}$ of sodium hydroxide $(\mathrm{BDH})$ in amount of distilled water then add $0.1069 \mathrm{~g}$ of potassium periodate (BDH) .Stir the mixture and dilute to the mark in $100 \mathrm{~mL}$ volumetric flask with distilled water. More dilute solutions were prepared daily by suitable dilution with distilled water.

\section{Pharmaceutical preparations of Thymol}

Pharmaceutical preparations were obtained from commercial sources.

1. Listerine-antiseptic (USA): containing $0.063 \%$ Thymol.

2. Breath $\mathrm{Rx}$ (mouth rinse-anti bacterialUSA): containing $0.060 \%$ Thymol.

\section{Procedure for Mouth washes}

Two types of mouth wash were analyzed by the developed methods, these include:

\section{1-Breath $R x$ (mouth rinse-anti bacterial-} USA): Usually this type of mouth wash containing $0.060 \%$ THY and to prepare a solution of drug transfer $20 \mathrm{~mL}$ of the pharmaceutical form to a $50 \mathrm{~mL}$ volumetric flask, add $5 \mathrm{~mL}$ of ethanol and dilute to the mark with distilled water. This stock solution has a concentration of $240 \mu \mathrm{g} \cdot \mathrm{mL}^{-1}$. Working solution of $100 \mu \mathrm{g} \cdot \mathrm{mL}^{1}$ was prepared by simple dilution of the stock solution with distilled water.

2-Listerine-antiseptic (USA):This form usually containing $0.063 \%$ of THY and to prepare a solution of drug transfer $20 \mathrm{~mL}$ of this preparation to a $50 \mathrm{~mL}$ volumetric flask then add $5 \mathrm{~mL}$ of ethanol and dilute to the mark with distilled water. This stock solution has a concentration of $252 \mu \mathrm{g} \cdot \mathrm{mL}^{-1}$. The working solution of $100 \mu \mathrm{g} \cdot \mathrm{mL}^{-1}$ was prepared by simple dilution of the stock solution with distilled water. 


\section{General FIA procedure}

Thymol concentrations in the range of 10-150 $\mu \mathrm{g} \cdot \mathrm{mL}^{-1}$ were prepared from the working solution of $1000 \mu \mathrm{g} \cdot \mathrm{mL}^{-1}$. A $150 \mu \mathrm{L}$ portion of THY was injected into the stream of $7 \times 10^{-4} \mathrm{M}$ of $2,4-\mathrm{DNPH}$ then the mixture combine with a mixture of $0.5 \mathrm{M} \mathrm{NaOH}$ with $5 \times 10^{-3} \mathrm{M}$ of $\mathrm{KIO}_{4}$ at T-link with a total flow rate of $2.4 \mathrm{~mL} \cdot \mathrm{min}^{-1}$ of the two channels, the resulting absorbance of the violet product was measured at $570 \mathrm{~nm}$ and a calibration graph was constructed.

Optimization of conditions were carried out on $50 \mu \mathrm{g} \cdot \mathrm{mL}^{-1}$ of THY.

\section{Results and Discussion}

Thymol forms violet colored product with 2,4-DNPH in the presence of a mixture of potassium periodate with sodium hydroxide. The batch method [20] for the determination of THY was adopted as a basis to develop FIA procedure. The absorption spectrum [20] of the colored product is shown that the product gave a maximum absorption at $570 \mathrm{~nm}$. The absorbance is directly related to the concentration of THY and can be used for its spectrophotometric determination. The development of the color product depends on the reaction conditions and was optimized as follows.

\section{Configuration Designs}

The FIA configuration used to determine THY was designed to provide different reactions conditions for magnifying the absorbance signal generated by reaction of THY with 2,4-DNPH in the presence of potassium periodate with sodium hydroxide. Maximum absorbance intensity was obtained when the sample was injected into a stream of $7 \times 10^{-4} \mathrm{M} 2,4-\mathrm{DNPH}$ and then combined with a mixture of $0.5 \mathrm{M} \mathrm{NaOH}$ with $5 \times 10^{-3} \mathrm{M}$ potassium periodate.

\section{Optimization of chemical parameters:}

Optimization of conditions were carried out using $50 \mu \mathrm{g} . \mathrm{mL}^{-1}$ of THY.

\section{Concentration of sodium hydroxide}

The effect of different concentrations of $\mathrm{NaOH}$ was studied in the range of 0.1 to $1 \mathrm{M}$. A concentration of $0.5 \mathrm{M}$ gave a highest absorbance and was chosen for further use Fig.(3).

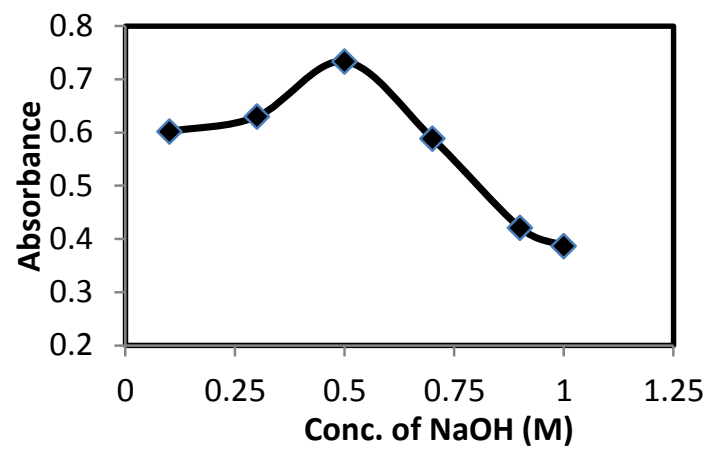

Fig.(3) Effect of the concentration of $\mathrm{NaOH}(\mathrm{M})$.

\section{Concentration of 2,4-DNPH}

The effect of various concentrations of 2,4DNPH solution were investigated in the range of 0.1 to $5 \mathrm{mM}$ using $0.5 \mathrm{M}$ of $\mathrm{NaOH}$. A concentration of $0.7 \mathrm{mM}$ gave a highest absorbance and was chosen for further use. The results are shown in Fig.(4).

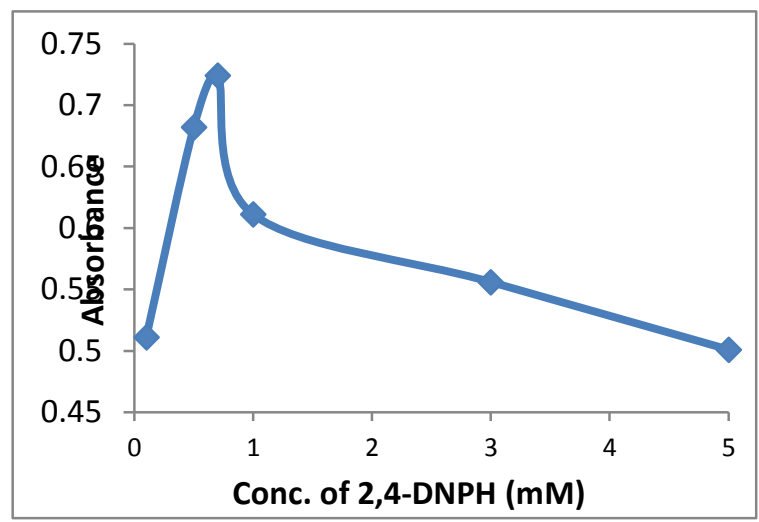

Fig.(4) Effect of the concentration of 2,4$\mathrm{DNPH}(\mathrm{mM})$ using $0.5 \mathrm{M} \mathrm{NaOH}$ and 50ppm THY.

\section{Concentration of potassium periodate}

The effect of different concentrations of potassium periodate were studied in the range of 1 to $50 \mathrm{mM}$ in $0.5 \mathrm{M} \mathrm{NaOH}$. A concentration of $5 \mathrm{mM}$ gave a highest absorbance and was chosen for further use Fig.(5). 


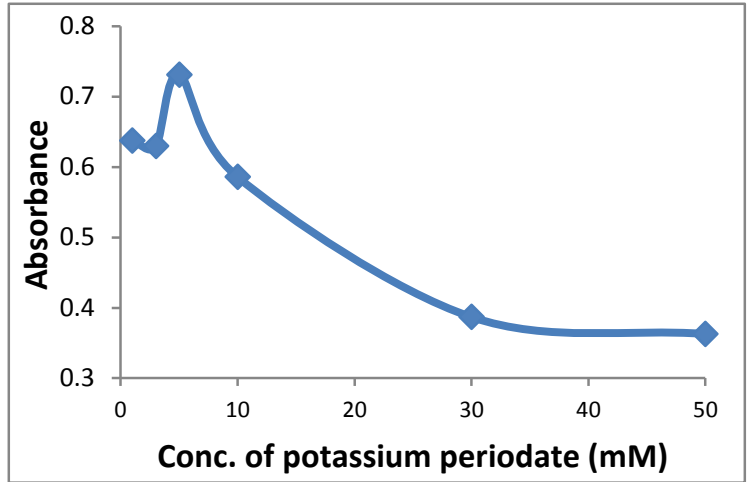

Fig. (5) Effect of the concentration of potassium periodate in $0.5 \mathrm{M} \mathrm{NaOH}(\mathrm{mM})$ using 50ppm THY.

\section{Optimization of manifold parameters}

\section{$>$ Effect of flow rate:}

The effect of total flow rate on the sensitivity of the colored reaction product was investigated in the range of $0.6-4 \mathrm{~mL} \mathrm{~min}^{-1}$. The results obtained showed that a total flow rate of $2.4 \mathrm{~mL} \mathrm{~min}^{-1},\left(1.2 \mathrm{~mL} \mathrm{~min}^{-1}\right.$ in each line $)$ gave the highest absorbance as shown in Fig.(6), and was used in all subsequent experiments.

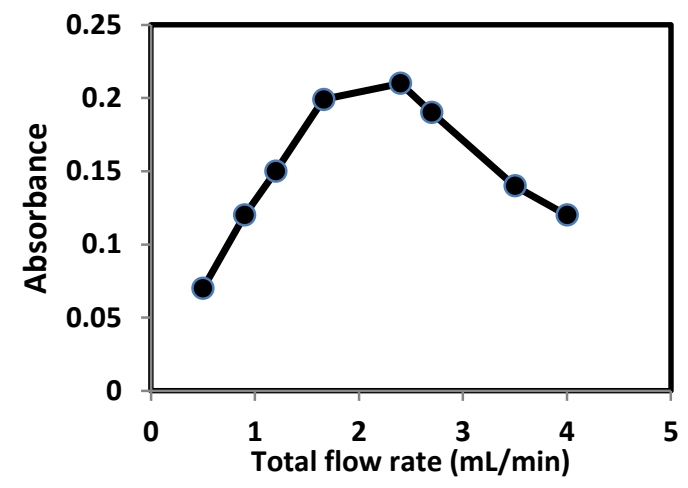

Fig.(6) Effect of the total flow rate ( $\mathrm{mL} / \mathrm{min})$.

\section{Effect of injection sample volume:}

The volume of the injection sample was varied between 50 and $250 \mu \mathrm{L}$ using different lengths of sample loop. The results Fig.(7) obtained showed that injected sample of $150 \mu \mathrm{L}$ gave the best absorbance.

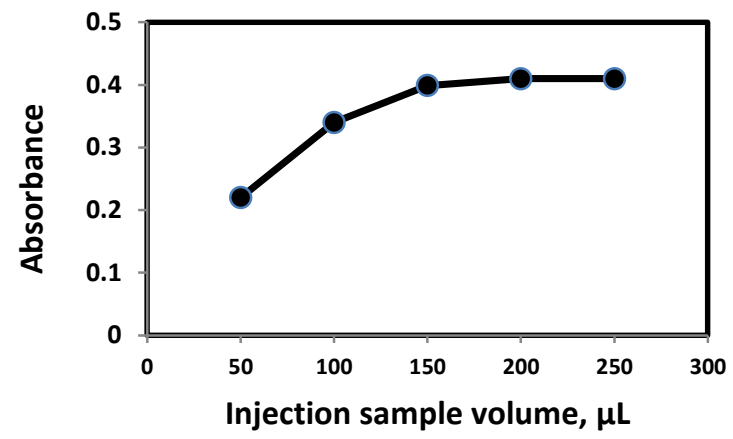

Fig. (7) Effect of the injection sample loop $(\mu L)$.

\section{Effect of reaction coil length:}

The coil length is an essential parameter that affects on the sensitivity of the colored reaction product and was investigated in the range of $25-250 \mathrm{~cm}$. the results obtained showed that a coil length of $100 \mathrm{~cm}$ gave the highest absorbance as shown in Fig.(8) and was used in all subsequent experiments.

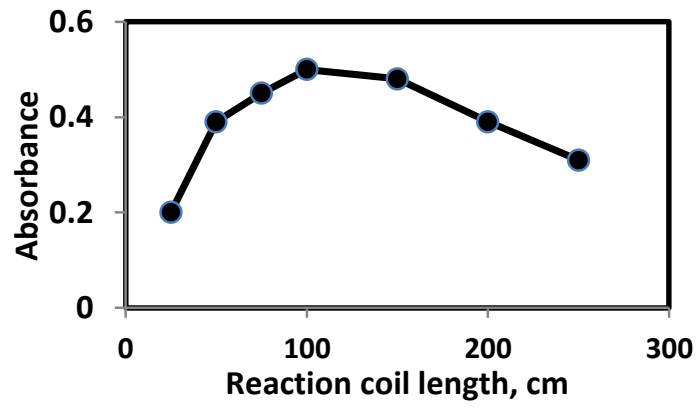

Fig.(8) Effect of the length of the reaction coil in $(\mathrm{cm})$.

\section{Analytical characteristics}

Analytical characteristics such as calibration curve Fig.(9), sampling rate, detection range, correlation coefficient, relative standard deviation (RSD) and limit of detection [21] of the method were determined for the above optimized conditions as shown in Table (1). In addition the precision of the method was evaluated by analyzing pure sample of THY in five replicate and a good repeatability was obtained and summarized in the same table. The reaction time is also an important parameter that affected the sample throughput and was investigated by calculating the interval time between the sample injection and appearance the end of signal. The sample through put was 60 samples $^{-1}$. 


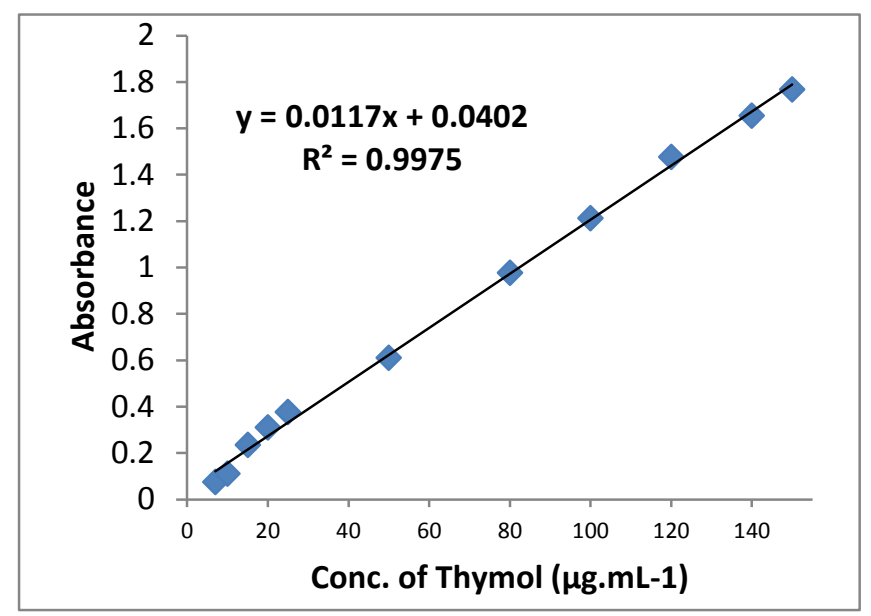

Fig. (9) Calibration graph of Thymol.

Table (1)

Analytical parameters of spectrophotometric method.

\begin{tabular}{|l||l||}
\hline \multicolumn{1}{|c||}{ Parameters } & \multicolumn{1}{c|}{ Value } \\
\hline \hline$\lambda_{\max (\mathrm{nm})}$ & 570 \\
\hline \hline Linearity range, $\mu \mathrm{g} \mathrm{\textrm {mL } ^ { - 1 }}$ & $10-150$ \\
\hline \hline Regression equation & $\mathrm{Y}=0.0117 \mathrm{X}+0.0402$ \\
\hline \hline Linearity $\left(\mathrm{r}^{2}\right)$ & 0.9975 \\
\hline $\begin{array}{l}\text { Limit of detection }( \\
\text { LOD* }\left(\mu \mathrm{g} \mathrm{mL}^{-1}\right)\end{array}$ & 5.0 \\
\hline $\begin{array}{l}\text { Relative standard } \\
\text { deviation }\left(\mathrm{RSD}^{2}\right)\end{array}$ & 1.55 \\
\hline \hline Average of recovery\% & 101.12 \\
\hline \hline Erel $\%$ & 1.12 \\
\hline \hline Color & violet \\
\hline \hline Sampling rate $\left(\mathrm{hr}^{-1}\right)$ & 60 \\
\hline
\end{tabular}

${ }^{*} L O D=\left(3 \sigma_{B} / S\right), \sigma_{B=}$ standard deviation of blank, $S=$ slope

\section{Analysis of Thymol pharmaceutical forms}

The proposed FIA method was practically applied for the quantitative estimation of THY in its pharmaceutical preparations (mouth wash formulation). Two types of mouth wash preparations containing $20 \mu \mathrm{g} \cdot \mathrm{mL}^{-1}$ THY were analyzed and they gave a good accuracy and precision as shown in Table (2). The results of the proposed method was compared successfully with the official method (British pharmacopeia method, BP) [1].

Table (2)

Application of the proposed and official methods for the determination of mouth wash containing Thymol.

\begin{tabular}{|c|c|c|c|}
\hline \multirow{2}{*}{$\begin{array}{c}\text { Pharmaceutical } \\
\text { samples } \\
\left(20 \mu \mathrm{g} . \mathrm{mL}^{-1}\right)\end{array}$} & \multicolumn{2}{|c|}{$\begin{array}{c}\text { Proposed } \\
\text { method }\end{array}$} & $\begin{array}{c}\text { Official } \\
\text { method [1] }\end{array}$ \\
\hline & $\begin{array}{c}\text { Recovery, } \\
\%\end{array}$ & $\begin{array}{c}R S D \\
\%\end{array}$ & $\begin{array}{c}\text { Recovery, } \\
\%\end{array}$ \\
\hline $\begin{array}{l}\text { Breath Rx } \\
\text { (Mouth wash) }\end{array}$ & 99.60 & 1.57 & 99.48 \\
\hline $\begin{array}{l}\text { Listerine (Mouth } \\
\text { wash) }\end{array}$ & 99.20 & 4.18 & 100.86 \\
\hline
\end{tabular}

Two test [21] (F-test and T-test) were applied to ensure if there is any significant difference between proposed FIA method and standard method (BP method) using 4-aminoantipyrine and potassium ferricyanide. In all cases, the calculated $\mathrm{F}$ and $\mathrm{t}$ values for method did not exceed the theoretical values, indicating that there is no significant difference between the two methods as regard accuracy (t-test) and precision (F-test) Table (3).

Table (3)

The comparison of the proposed method with standard method using $t$ - and $F$-statistical tests.

\begin{tabular}{|c|c|c|c|c|}
\hline \multirow{2}{*}{$\begin{array}{c}\text { The pharmaceutical } \\
\text { preparations } \\
\left(20 \mu \mathrm{g} . \mathrm{mL}^{-1}\right)\end{array}$} & \multicolumn{2}{|c|}{ The proposed method } & \multicolumn{2}{|c|}{ The official method[1] } \\
\hline & Recovery \% & $\left(X i-X i{ }^{-}\right) 1^{2}$ & Recovery \% & $(X i-X i)^{-}{ }^{2}$ \\
\hline Pure Thymol & 101.12 & 1.316 & 98.00 & 2.094 \\
\hline Breath Rx & 99.60 & 0.139 & 99.48 & 0.001 \\
\hline Listerine & 99.20 & 0.598 & 100.86 & 1.997 \\
\hline $\mathrm{S} * *$ & \multicolumn{2}{|c|}{$1.239\left(\mathrm{~S}_{1}^{2}=1.026\right)$} & \multicolumn{2}{|c|}{$\left(\mathrm{S}_{2}^{2}=2.046\right)$} \\
\hline t $(2.776)^{*}$ & \multicolumn{2}{|c|}{0.521} & \multicolumn{2}{|c|}{$\left(\mathrm{n}_{1}+\mathrm{n}_{2}-2\right)=4$} \\
\hline $\mathrm{F}(19.000)^{*}$ & \multicolumn{2}{|c|}{1.994} & \multicolumn{2}{|c|}{$\mathrm{n}_{1}=3, \mathrm{n}_{2}=3$} \\
\hline
\end{tabular}

*Table value.

$* *_{s}$ pooled standard deviation $=\sqrt{\frac{\left(n_{1}-1\right) S_{1}^{2}+\left(n_{2}-1\right) S_{2}^{2}}{n_{1}+n_{2}-2}}, t=\frac{\left|\bar{X}_{1}-\bar{X}_{2}\right|}{S \sqrt{\left(\frac{1}{n_{1}}+\frac{1}{n_{2}}\right)}} S_{1}^{2}=$ variation $=\frac{\sum(X i-\bar{X})_{1}^{2}}{n_{1}-1}$ and $S_{2}^{2}=\frac{\sum(X i-\bar{X})_{2}^{2}}{n_{2}-1}$ 


\section{Conclusions}

Until now the literature contains only a few flow injection methods for determination of THY in raw and pharmaceutical preparations. This research offers a developed automated simple, rapid, low cost method and fairly selective than some of the reported methods. Moreover, the proposed procedure is very economical and cheap especially when compared to other methods such as chromatography, electrosensors and capillary electrophoresis and have a good linearity and sensitivity. Finally, the proposed method was applied to the analysis of THY in wash mouth preparations, and statistical analysis between the proposed method and the official method.

\section{References}

[1] British Pharmacopoeia on CD-ROM. 1998. Version 5, $3^{\text {rd }}$ Ed., Vol.1, Copyright by System Simulation Ltd., The Stationery Office Ltd., London, 1288.

[2] Norwitz, G.; Nataro, N.; Keliher, P. N., "Study of the Steam Distillation of Phenolic Compounds Using Ultraviolent Spectrometry", Anal. Chem. 58 (639-640): 641, 1986.

[3] Mezzoug, N.; Elhadri, A.; Dallouh, A.; Amkiss, S.; Skali, N.S.; Abrini, J.; Zhiri, A.; Baudoux, D.; Diallo, B.; El Jaziri, M.; Idaomar, M. "Investigation of the mutagenic and antimutagenic effects of Origanum compactum essential oil and some of its constituents'. Mutation Research/Genetic Toxicology and Environmental Mutagenesis., 629 (2): 100, 2007.

[4] Rafiul, M.D.; Ansari, S.H.; Abdulkalam, N. and Kamran, J.N. "Validated HPLTC analysis method for quantification of thymol content in trachyspermum ammiand polyherbal unani formulation arq zeera', Int J Pharm.Sci, 4: 478-484, 2012.

[5] Poor, H.H.; Shekarchi, M.; Khanavi, M.; Adib, N. and Amir, M. "A validated HPLC method for the analysis of thymol and carvacrol in thymus vulgarisL. volatile oil', Pharma. magazine, 6:154-158, 2010.

[6] Thompson, R.D.; Carlson, M. "Determination of Thymol in halothane anaesthetic preparations by high- performance liquid chromatography', J. Pharm. Biomed. Anal., 7:1199-1206, 1989.

[7] Ji, L.; Wang, Y.Y.; Tong, Y; Li, X.D.; Feng, X.F.; Hang, L.Q. and Zhou, G.P. "Determination of carvacrol and Thymol in Mosla chinensis by HPLC", Zhongguo Zhong Yao Za Zhi, 29: 1030-1032. 2004.

[8] Kang, L.I.; Jinsong, Y. and Weiwei, S.U. "Determination of Liquiritin, Naringin, Hesperidin, Thymol, Imperatorin, Honokiol, Isoimperatorin, and Magnolol in the Traditional Chinese Medicinal Preparation Huoxiang-zhengqi Liquid Using High-performance Liquid Chromatography", Yakugaku Zasshi, 126:1185-1190, 2006.

[9] Badertscher, R.; Kilchenmann, V.; Liniger, A. and Gallmann, P. "Determination of 1,4dichlorobenzene, naphthalene and thymol residues in honey using static headspace coupled with GC-MS" Journal of Api Product \& Api Medical Science, 2 (3): 8792, 2010.

[10] Angelov, I.; Villanueva, D.; Roumiana, B.; Stateva, P.; Reglero, P.; Ibañez, E.; and Fornari. T. "Extraction of thymol from different varietyiea of thyme plants using green solvents", Cartagena de Indias, 3:1-7, 2013.

[11] Fibranz, L.; Blake, M.I. and Miller, C.E. "Colorimetric determination of Thymol in thyme oil', J. Am. Pharm. Asso., 47: 133$135,1985$.

[12] Zhao, X.; Du, Y.; Ye,W.; Lu,D.; Xia, X. and Wang, C. "Sensitive determination of Thymol based on $\mathrm{CeO}_{2}$ nanoparticledecorated graphen hybrid film', New J.Chem, 37 : 4045-4051. 2013.

[13]Al-Neaimy, U.I.S. "Spectrophotometric determination of thymol in pharmaceuticals with Gibb's reagent', J. Edu. and Sci., 22:125-136, 2009.

[14] Al-Enizzi, M.S.; Al-Sabha ,T.N. and A 1Ghabsha, Th. S., "Use of charge transe for complex formation reaction in spectrophotometric microdetermination of some drugs", Jordan J. of Chem., 7:87-102. 2012.

[15] Korany, M.A.; Seif El-Din, A.A. and Abdel-Salam, N.N. "Application of second derivative ultraviolet spectrometry Part III : Determination of eugenol, Thymol and 
anethole in volatile oils', Anal. Lett., 17: 483-490,1984.

[16] Glaudia, K.; Gudrun, A.; Eleonora, S. and Markus, V. "Determination of thymol in human plasma by automated headspace solid-phase micro extraction-gas chromatographic analysis', J. of Chromatogr. B, 767:11-18, 2002.

[17] Kohlert, C.; Abel, G.; Schmid, E. and Veit, M. "Determination of Thymol in human plasma by automated headspace solid-phase microextraction-gas chromatographic analysis", J. Chromatogr. B Analyt. Technol. Biomed. Life Sci., 767:11-8, 2002.

[18] Giovana, M.F.; Pierina, S.B.; Maria, P.; Silvia, H. and Pereira, A. "Determination of Thymol and Carvacrol in Plasma and Milk of Dairy Cows using Solid-Phase Microextraction', J. Braz. Chem. Soc., 24 : 837-846, 2013.

[19] Al-Abachi, M.Q. and Al-Ward, H.S. "Batch and flow-injection spectrophotometric determination of thymol using procaine hydrochloride as a new chromogenic reagent', J. Baghdad for Sci., 9: 302-310, 2012.

[20] Fadhil G., "Spectrophotometric determination of Thymol in its pharmaceutical preparations', Iraqi Journal of science, 55(1):27-34, 2014.

[21] Sanders, D.H. and Murph, A..F. 1976. Statistics, Mc.Graw-Hill, New York.

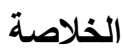

يتضمن البحث وصف طريقة طيفية لتقدير للثايمول

باستخدام تقنية الحقن الجرياني. اعتمدت الطريقة على ازدواج

المستحضر المذكور مع كاشف r،یـ- ثنائي نيترو فنيل

هيدرازين في الوسط القاعدي بوجود بيرايودات البوتاسيوم

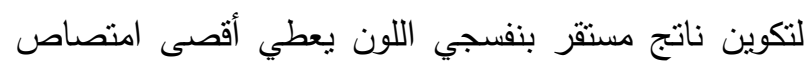

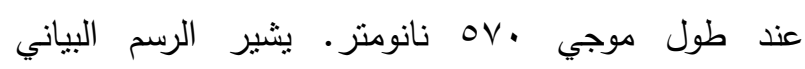

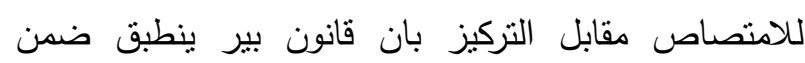

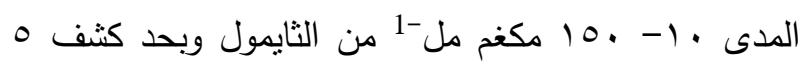

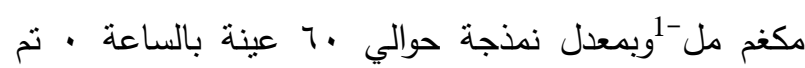

تطبيق الطريقة المقترحة بنجاح في تقدير الثنايمول في بدي 